\title{
EL USO SABIO DE LA AUSENCIA EN LA AVENTURA INTELECTUAL DE MACEDONIO FERNANDEZ
}

\author{
POR \\ GERARDO MARIO GOLOBOFF \\ Université de Toulouse-Le Miral
}

La extraña materialidad de «lo vivible» fue una preocupación que acosó de modo constante a Macedonio; la otra fue (para decirlo también con palabras que quisieran ser suyas) la inexistente vivencialidad de «la leíble». Ambas inquietudes podrían resumirse en el título que eligió para su primer libro, donde la afirmación de una existencia trascendente (de Pasión o de Arte, como él las quería, no de mera presencia) prepondera sobre la inocua mirada biológica: No toda es vigilia la de los ojos abiertos (1928).

Asustado por las exigencias de la vida, temblando de frío o cubierto. por un poncho de vicuña bajo el cual asomaban dos o tres pullóveres de lana, horrorizado por la posibilidad del dolor físico y por el miedo a la muerte imprevista, este «semidiós acriollado» - como lo definiera Jorge. Luis Borges- la dejó transcurrir en un inconmovible estado de duda. Con respecto a la otra, la hipotética existencia real de todo lo leíble, fue, para gozo de nuestra literatura latinoamericana, enormemente más riguroso. No caben, con referencia al arte o a la narrativa, las más mínimas dudas en su espíritu: sus personajes son «caballeros-no-existentes», puesto que él no confunde los planos: "Yo quiero que el lector sepa siempre que está leyendo una novela y no viendo un vivir, no presenciando 'vida'» ${ }^{1}, y$, más. adelante, justificando sus incongruencias «para desafiar con lo artístico lo verosímil, lo pueril verosímil», subraya:

Hacer novela o teatro con dementes es como hacer ciencia enpezando por negar la causalidad, es elegirse el poco trabajo de explicarlo todo por la demencia, usar la demencia como coordinadora de novela,

${ }^{1}$ Macedonio Fernández, Museo de la novela de la Eterna (Buenos Aires: Centro Editor de América Latina, 1967), p. 39. 
hacer realismo incomprobable para el lector, ya que lo inconexo y absurdo es la verosimilitud de la demencia. La locura en arte es una negación realista del arte realista. [...] Yo no doy personajes locos, doy lectura loca y precisamente con el fin de convencer por arte, no por verdad $^{2}$.

Lo interesante es que a partir de ese rigor se insinúa un cierto esbozo autobiográfico de Macedonio (más, me parece, que a través de ciertos textos que aparentemente se proponen serlo). De él puede desprenderse una cierta reflexión escrita, historizada, sobre sus relaciones con el mundo, aunque ella no sea, claro está, escalonada, sistematizada, dirigida y, mucho menos, pensada en función de "construir un yo» para otros, ni para Dios, de cuyas preocupaciones biográficas tenía serias dudas, ni para sí mismo, en quien no creía más.

De allí, tal vez, la poca importancia que asigna a su diario vivir (se hacen tan famosas sus mudanzas, que llega a comunicar, en lugar de su nueva dirección, "mi actual cambio de domicilio es...»). No le merecen atención las inhóspitas pensiones que habita, los textos que escribe y olvida en roperos, armarios y mesas de bares, el prejuicio del futuro. Sólo una o dos cosas de su vida le preocupan verdaderamente, o así parece demostrarlo la insistencia con que de ellas habla y escribe. Una es su llegada al mundo, hecho sobre el cual da cifras cambiantes: «El Universo o Realidad y yo nacimos en $10^{\circ}$ de junio de 1874 y es sencillo añadir que ambos nacimientos ocurrieron cerca de aquí y en una ciudad de Buenos Aires» ${ }^{3}$, o bien: «Nací tempranamente: en una sola orilla (aún no me he secado del todo) del Plata. Me encontraba en Buenos Aires, a la sazón; era en 1875: fue el año de la revolución del 74, como después tuvimos un año de la revolución del 90 » $^{4}$, o aún: «Nací el $1 .^{\circ}$ de octubre de 1875 y desde este desarreglo empezó para mí un continuo vivir» ${ }^{5}$. La otra cosa que le preocupa es la muerte, presentida como pérdida de amor, no de vida física, concepción que se delinea ya en uno de sus tempranos poemas: «No es Muerte la libadora de mejillas, / Esto es Muerte: el Olvido de ojos mirantes» («Hay un morir», 1912).

Entre estas dos circunstancias (tan imprecisa la primera como la segunda: baste recordar que en 1905 habla en una carta de trabajos a realizar en 1906 «si vivo») puede recortarse una imagen retrospectiva (siempre indirecta) tanto de su vida como de sus quehaceres literarios. Alusio-

${ }^{2}$ Museo..., op. cit., p. 66.

${ }^{3}$ Papeles de Macedonio Fernández (Buenos Aires: EUDEBA, 1964), p. 49.

${ }^{4}$ Papeles..., op. cit., p. 46.

${ }^{5}$ Papeles..., op. cit., p. 37. 
nes, en realidad, con las que hay que ir componiendo esa autobiografía salteada propia de Macedonio, quien, como puede saberse, despreciaba un tanto las «lecturas corridas», las autobiografías mismas («la forma más embustera de arte que se conoce») ${ }^{6} \mathrm{y}$, por supuesto, la fama: «con la velocidad alcanzada hoy por la posteridad el artista le sobrevive y al día siguiente sabe si debe o no escribir mejor o si ya lo ha hecho tan bien que debe contenerse en la perfección de escribir» ${ }^{7}$.

Sobre ese collage displicente, irrenunciablemente irónico consigo mismo, salpicado de profundas verdades y de inocentes mentiras, pueden extenderse algunas de las coordenadas de un Macedonio pensado por sí mismo, un Macedonio cuyas indisciplinas vitales no permiten más que ese esbozo o, como lo llamara Noé Jitrik, ese «retrato discontinuo» ${ }^{8}$. Se fusionan, naturalmente, de un modo ya tiránico, esa persona civil plena de originalidad y su "persona de autor», no menos singular, puesto que en la temprana subversión de los elementos del relato que ella propusiera están los gérmenes de la renovación y de la vitalidad de nuestra actual narrativa.

Y creo que es a la luz de uno de los más importantes aspectos del conjunto teórico en que desarrolló su ataque contra el arte verosímil, contra el relato tradicional, contra la consecuente «complacencia» de lectura, que pueden también seguirse y comprenderse ciertas líneas esenciales de lo que, siendo, como todo discurso, apelación al otro para la construcción del yo (o, como diría Lacan, «campo de la realidad transindividual del sujeto» ${ }^{9}$ ), está lejos de ser una edificación heroica del yo, trazo apolíneo de la propia estatura.

Ese aspecto de su reflexión teórico-práctica en el que conviene detenerse un instante es, sin duda, su puesta en tela de juicio del fenómeno de identificación en la lectura o en la visión, ya sea identificación con los sentimientos del personaje, con los del héroe, con los del autor. Macedonio impugna desde su raíz la concepción antropocéntrica del personaje como sujeto de aventuras en un mundo presumiblemente semejante al mundo real, $y$, consiguientemente, hace caer la noción del personaje individual e identificado con individuos. Crea (porque no solamente predica, sino que pone en marcha esa teoría de su «primera novela buena») el personaje que no existe, Deunamor, el No Existente Caballero, «cuya consistente fantasía es garantía de firme irrealidad» ${ }^{10}$ y, junto a él, los «perso-

\footnotetext{
${ }^{6}$ Papeles..., op. cit., p. 50.

7 Museo..., op. cit., p. 44.

${ }^{8}$ Noé Jitrik, «Retrato discontinuo de Macedonio Fernández», en Crisis, Buenos Aires, núm. 3, julio 1973, pp. 44-49.

${ }^{9}$ Jacques Lacan, Écrits I (París: Éditions du Seuil, Col. Point, 1966), p. 134.

${ }^{10}$ Museo..., op. cit., p. 42.
} 
najes efectivos», los «personajes frágiles», los «desechados ab initio» y muchos otros por el estilo, donde no falta también el «personaje perfecto, por genuina vocación, contento de ser personaje», y cuyo nombre es, naturalmente, «Simple» ${ }^{11}$.

Con todo ello, descentra lo personal de la región del arte, y hasta estoy tentado de decir que postula un "extrañamiento», recordando involuntarias semejanzas con ideas de Brecht, las que, por un costado bastante diferente al de Macedonio obviamente, buscaba acaso no muy diferentes objetivos, puesto que a uno y otro serían aplicables las palabras de Althusser referidas al primero: «... pour produire dans le spectateur une nouvelle conscience, vraie et active, le monde de Brecht doit nécessairement exclure de soi toute prétention à se ressaisir et figurer exhaustivement sous la forme d'une conscience de soi» ${ }^{12}$. Lo que para el marxista Brecht fue necesidad de distanciamiento y de recuperación de objetividad del espectador con el objeto de lograr una más correcta elaboración del juicio crítico y una participación más consciente en la vida social, para el así catalogado «idealista» Macedonio fue también imperiosa necesidad de problematización, de separación, de lucidez: «Hay un lector con el cual no puedo conciliarme: el que quiere lo que han codiciado para su descrédito todos los novelistas, lo que dan éstos a ese lector: la Alucinación. [...] En el momento en que el lector caiga en la Alucinación, ignominia del Arte, yo he perdido, no ganado lector» ${ }^{13}$. $[\ldots]$ «... ante lo difícil que es evitar la alucinación de realidad, mácula del arte, he creado el único personaje hasta hoy nacido cuya consistente fantasía es garantía de firme irrealidad en esta novela indegradable a real: el personaje que no figura» ${ }^{14}$.

Es por eso que crea ese universo inconfundible con la vida, «indegradable a real», y en el que, por tanto, no habrá ensueño de conquista para el narcisismo del creador: "Nací, otros lo habrán efectuado también, pero en sus detalles es proeza. Lo tenía olvidado, pero lo sigo aprovechando a este hecho sin examinarlo, pues no le hallaba influencia más que sobre la edad» ${ }^{15}$.

Es probable que algunos gestos vitales de Macedonio inclinen a pensar que de alguna manera él también elaboraba un personaje con su propia vida, pero la falta de seriedad con que los asumió hacen suponer que su programa, si es que alguno tuvo, estaba mucho más centrado en las pre-

11 «Dos personajes desechados», en Museo..., op. cit., pp. 77-80.

${ }^{12}$ Louis Althusser, "Notes sur un théâtre matérialiste», en Pour Marx (París: Maspero, 1974), p. 144.

${ }^{13}$ Museo..., op. cit., p. 39.

${ }^{14}$ Museo..., op. cit., pp. 41-42.

${ }^{15}$ Papeles..., op. cit., p. 50. 
ocupaciones filosóficas y estéticas que en ciertos actos contingentes: montar una colonia saintsimoniana en el Paraguay hacia 1897, ejercer durante años la profesión de abogado, proyectar ser candidato a presidente de la República Argentina en 1927 (porque eso era más fácil que abrir una cigarrería, ya que muchísima gente quería ser propietaria de quioscos, pero pocos ambicionaban ser presidentes), eran actividades mundanas, indignas de mayor mención. Rodearse, en cambio, de jóvenes escritores en un café de barrio para hablarles y hacerles hablar de Schopenhauer, de Berkeley, del universo, escribir y, sobre todo, pensar, suponía una disposición del espíritu completamente distinta; con ella nada era patrimonio de uno, todo podía transmitirse y saberse.

Uno de sus más íntimos biógrafos (si así podemos llamarle), Jorge Luis Borges, nos cuenta de él que «trataba de ocultar, no de exhibir, su inteligencia extraordinaria; hablaba como al margen del diálogo y, sin embargo, era su centro. Prefería el tono interrogativo, el tono de modesta consulta, a la afirmación magistral. Jamás pontificaba; su elocuencia era de pocas palabras y hasta de frases truncas. El tono habitual era de cautelosa perplejidad». Y agrega: «Vivía (más que ninguna otra persona que he conocido) para pensar. [...] Su pensamiento era tan vívido como la redacción de su pensamiento. [...] La actividad mental de Macedonio era incesante y rápida, aunque su exposición fuera lenta; ni las refutaciones ni las confirmaciones ajenas le interesaban.» Con referencia al poco valor que daba a sus escritos, y al hecho de que por eso muchos se hayan perdido de manera quizás irrecuperable, comenta Borges que, al reprocharle esa distracción, Macedonio le respondió que «suponer que podemos perder algo es una soberbia, ya que la mente humana es tan pobre que está condenada a encontrar, perder y redescubrir siempre las mismas cosas», y para ilustrar acabadamente ese retrato, que juzgo útil si se quiere medir la imagen que Macedonio tenía de sí, nos dice el autor de Ficciones: «La indolencia nos mueve a presuponer que los otros están hechos a nuestra imagen; Macedonio Fernández cometía el error generoso de atribuir su inteligencia a todos los hombres» ${ }^{16}$.

Como se ve, la pretensión, en esas condiciones, de elaborar una historia más o menos ejemplar de sí mismo hubiera sido incongruente. Es más, en su literatura aparece claramente enunciado el carácter de despojamiento que asigna a los descubrimientos de la mente y a la práctica escrituraria misma, y el sentido que ese despojamiento tiene en el conjunto

${ }^{16}$ Macedonio Fernández. Selección y prólogo de Jorge Luis Borges (Buenos Aires: Ediciones Culturales Argentinas, Biblioteca del Sesquicentenario, 1961). Reproducido en Jorge Luis Borges, Prólogos (Buenos Aires: Torres Aguiero Editor, 1975), pp. 52-61. 
de su actividad literaria. En una de las primeras páginas de su Museo..., que figura como «Dedicatoria a mi personaje de la Eterna», escribe:

La Realidad y el Yo, o principalmente el Yo, la Persona (haya o no mundo) sólo se cumple, se da, por el momento altruístico de la piedad (y de la complacencia) sin fusión, en pluralidad. El acto no instintivo de Piedad, reteniéndose el lúcido discernimiento de pluralidad, sin confusión, del Otro con el Nosotros, es la finalidad de Haber Algo, del Mundo, y es lo solo ético: ser otro todavía en el hacerlo todo por un otro ${ }^{17}$.

En ese deseo de no confundir el Otro con el Nosotros, en esa suprema generosidad intelectual que consiste en el hacer sólo por otro, halla también su origen el insistente carácter de obra abierta de toda su producción, la que, sin ir más lejos, encuentra un buen ejemplo en $M u s e o . . .$, que termina con un prólogo final titulado «Al que quiera escribir esta novela», y donde, anticipándose en muchos años a Umberto Eco y sus recientes investigaciones, «deja autorizado a todo escritor futuro de impulso y circunstancias que favorezcan un intenso trabajo, para corregirlo y editarlo libremente, con o sin mención de mi obra y nombre. No será poco el trabajo. Suprima, enmiende, cambie, pero, si acaso, que algo quede» ${ }^{18}$.

Museo de la novela de la Eterna es un texto que Macedonio pensaba publicar y hacer vender junto a Adriana Buenos Aires; ésta llevaría como subtítulo «última novela mala» y aquélla «primera novela buena», con un prólogo en común titulado «Lo que nace y lo que muere»; en común, ya que en el proyecto macedoniano no se trataba de dos textos, sino de uno solo, el que justamente demostraría en esa indisolubilidad su consistencia. No sabemos qué impedimentos frustraron la edición; acaso para la época fuera descabellada. Hoy, redescubierto el Tristram Shandy, popularizado el Ulises, aclamada (para no hablar sino de las letras hispanoamericanas) Rayuela (cuyo Morelli es una inteligente transposición macedoniana), es decir, admitidos todos los experimentos, quizás el proyecto de Macedonio habría encontrado recepción y hasta promoción. Pero el caso es que $\mathrm{Mu}$ seo... es una novela en la que nada se cuenta y en la que, a través de sus 56 prólogos, 20 capítulos y algunos títulos aislados, se intenta dar cuerpo a lo que bien se ha llamado la «novela futura» ${ }^{19}$.

Algunos de esos copiosos prólogos contienen datos para el problema que nos ocupa: son el $4 .^{\circ}$ ( $\left(\right.$ Prólogo a mi persona de autor»), el $6 .^{\circ}(« \mathrm{E} 1$

${ }^{17}$ Museo..., op. cit., p. 11.

${ }^{18}$ Museo..., op. cit., p. 236.

19 Noé Jitrik, «La "novela futura' de Macedonio Fernández», en El fuego de la especie (Buenos Aires: Siglo XXI Argentina, 1971), pp. 151-182. 
autor también habla»), el $12 .^{\circ}$ («Nuevo prólogo a mi persona de autor»), el 39. («Al autor [de la novela] ¿no le sucede nada?») y el siguiente («Prólogo de desesperanza de autor»). En ninguno de ellos se acomete con cierta seriedad lo que podríamos denominar, aun retaceadamente, el género autobiográfico. Sírvanos como ejemplo más ilustrativo un fragmento del segundo de los mencionados prólogos («El autor también habla»):

Pretendo... hacer la primera «novela», no del día en que áparezca, por la mañana, que en esto todas tuvieron su minuto de primeras; me he retardado demasiado en Literatura; me urge madrugar, pues para algo se apura el demorado: para llegar adonde no sea tarde, y yo he visto que no es tarde en el género «novela»: lo empezará un moroso ${ }^{20}$.

Esta declaración, unida a muchas otras de similares características, entre las que se destaca la que luego transcribiré, podría, con las limitaciones del caso, cumplir con ciertas cláusulas del «pacto autobiográfico», pero, para mantener el lenguaje jurídico que utiliza Philippe Lejeune ${ }^{21}$, siempre que dicho pacto se celebre "con beneficio de inventario», no sólo porque los requisitos formales se cumplen muy parcialmente, sino también porque la «historia» se reduce aquí a un presente en el que lo que interesa de la personalidad autoral es el cómo y el por qué se le ha ocurrido este tipo de novela, único problema sobre el que dirige la atención del lector.

No obstante, me parece útil destacar que en el «Nuevo prólogo a mi persona de autor» hallamos afirmaciones que bien podrían ser el ápice de una cierta construcción del yo, si bien basada en un programa inverso de desmitificación del yo:

Es muy sutil, muy paciente, el trabajo de quitar el yo, de desacomodar interiores, identidades. Sólo he logrado en toda mi obra escrita ocho o diez momentos en que, creo, dos o tres renglones conmueven la estabilidad, unidad de alguien, a veces, creo, la mismidad del lector. $\mathrm{Y}$ sin embargo pienso que la Literatura no existe porque no se ha dedicado únicamente a este efecto de desidentificación, el único que justificaría su existencia y que sólo esta belarte puede elaborar. Quizá la Pintura o la Danza podrían también intentarlo ${ }^{22}$.

Una frase que bien podía haber servido como presentación de mi trabajo figura poco antes: «Hágase el mérito de haber vivido construyéndome la

${ }^{20}$ Museo..., op. cit., p. 23.

${ }^{21}$ Philippe Lejeune, «Le pacte autobiographique», en Poétiqué, París, núm. 14; Du Seuil, 1973, pp. 137-162.

${ }^{22}$ Museo..., op. cit., p. 35. 
metafísica de un todo-amante, sin interesarme en hacer la mía: tal como yo soy no merezco ni explicación ni eternidad...» ${ }^{23}$. Sabemos ya, además, que el «anhelo que me animó en la construcción de mi novela fue crear un hogar, hacerla un hogar para la no-existencia en que necesita hallarse Deunamor, el No Existente Caballero» ${ }^{24}$.

Si bien se observa, se verá que lo común a todas estas declaraciones es en el fondo la negación absoluta de esa «persona de autor». Nos enfrentamos así con un cierto tipo de construcción carnavalesca (absorbida y practicada hoy por la llamada novela polifónica), de la que escribe Julia Kristeva: «Ainsi la scène du carnaval, où la rampe et la 'salle' n'existent pas, est scène et vie, jeu et rêve, discours et spectacle... ${ }^{25} \mathrm{O}$ sea, una escena sin representación, donde el autor, al incluirse en el sistema mismo que construye, desaparece como tal, «il n'est rien ni personne, mais la possibilité de permutation de $\mathrm{S}$ (sujet de la narration) à $\mathrm{D}$ (destinataire), de l'histoire au discours et du discours à l'histoire. Il devient un anonymat, une absence, un blanc, pour permettre à la structure d'exister comme telle» ${ }^{26}$.

Estas ideas pueden llevarnos a comprender, me parece, ese entramado macedoniano, que en realidad no es sino un largo monólogo en el que múltiples superficies y expresiones se entrecruzan, un encadenamiento de centros en el que Macedonio nos expone su Estética y, con ella, sus contribuciones y hasta (por qué no) la conciencia de sus méritos al producirla, pero una exposición en la cual prevalece siempre esa exacta noción de no pertenencia, de no propiedad, de despojo, a través de la cual se hace visible la invisibilidad de su portavoz. Se podría decir de este autor lo que él mismo escribe de ese personaje llamado «El hombre que fingía vivir»: «él ejecuta la Ausencia realizada por fin en arte» ${ }^{27}$.

Es justamente sobre este tema que quisiera terminar mi exposición. En un trabajo escrito poco después de la muerte de Macedonio, Ana María Barrenechea traza un puntual itinerario de su metafísica de la nada, y demuestra que ésta se basa precisamente en la negación de la materia y del yo como centro de la existencia, siendo la broma el pivote fundamental de la estrategia discursiva para sostenerla. «Pero se puede reconocer - aclara Ana María Barrenechea- que el humorismo de Macedonio Fernández rebasa el mero jugueteo verbal, y crea bajo la aparente dispersión

${ }^{23}$ Museo..., op. cit., p. 34.

${ }^{24}$ Museo..., op. cit., p. 26.

${ }^{25}$ Julia Kristeva, «Le mot, le dialogue et le roman», en Recherches pour une sémanalyse (París: Éditions du Seuil, 1969), p. 161.

${ }^{26}$ Julia Kristeva, op. cit., p. 156.

${ }^{27}$ Museo..., op. cit., p. 67. 
un mundo del no-ser, nítido y coherente ${ }^{28}$. Es dentro de esa organización de la no existencia donde pienso que deberían investigarse las pretensiones autobiográficas de Macedonio, sintiéndose tal vez ocasional demiurgo de esa irrealidad, pero también su víctima ineluctable: una vez puesto en funcionamiento el proceso por el que la escritura revela el anonimato creador no hay individualidad medianamente lúcida que pueda hacerlo retroceder.

$\mathrm{Si}$ algún lugar puede entonces pretender ocupar Macedonio con sus alusiones autobiográficas es ése de la Ausencia: nacer como un venir recién, como un faltar, crear la inexistencia, estar en la delgada lámina entre lo que nace y lo que muere. «El Museo —escribe un ensayista argentinohabla del libro 'vacío y perfecto': la cópula que equipa esos dos adjetivos demuestra cómo se implican en su pensamiento. La escritura da cuenta cabal de la realidad en la medida en que da cuenta de su inexistencia o su incertidumbre, de las condiciones en que podría ser constituida. Por eso la escritura más verdadera le parecía la de los prólogos: un discurso sobre la ausencia del texto para un texto que habla sobre la ausencia de lo real» ${ }^{29}$. Y la primerísima página de Museo lo anuncia: se trata de la «presentación en el arte, y en la vida, de un uso sabio de la Ausencia» ${ }^{30}$. Con esa convicción de la realidad y de la necesidad de la ausencia, la única fuente de presente posible parece ser la del nacimiento, el único testimonio si se quiere del no-ser del no-ser: por eso la búsqueda y la recurrencia sobre la fecha, sobre la circunstancia; por eso la mentira o el lapsus, y por eso también la ilusión del absoluto en la construcción de un proyecto desmesurado donde no puede sentir sino la ambición de un descubrimiento que lo sobrepasa y, con ella, la certeza de un fracaso que le hace escribir: "Yo no encontré una ejecución hábil de mi propia teoría artística» ${ }^{31}$. Palabras que bien podrían servir además de corolario para el intento que he tratado de exponer en estas líneas.

${ }^{28}$ Ana María Barrenechea, «Macedonio Fernández y su humorismo de la nada», en Buenos Aires literaria, núm. 9, Buenos Aires, junio 1953, p. 25.

${ }^{29}$ Néstor García Canclini, «Macedonio Fernández, el fundador», en Nuevos Aires, Buenos Aires, núm. 7, abril-mayo-junio 1972, p. 39.

${ }^{30}$ Museo..., op. cit., p. 9.

${ }^{31}$ Museo..., op. cit., p. 24. 
